\title{
A prospective study comparing induction chemotherapy followed by chemoradiation versus chemoradiation alone in stage III non-small cell lung cancer
}

\author{
K Sardar P. ${ }^{1}$, R Shenoi L. ${ }^{2 *}$
}

DOI: https://doi.org/10.17511/ijmrr.2020.i01.12

\author{
1 Pritam K Sardar, Clinical Tutor, Department of Radiotherapy, Malda Medical College and Hospital, Malda, West Bengal, India. \\ 2* Lekshmi R Shenoi, Post Graduate Trainee, Department of Radiotherapy, IPGMER and SSKM Hospital, Kolkata, West Bengal, India.
}

Background: Although concurrent chemoradiation (CCRT) is the standard of care for stage III nonsmall cell lung cancer(NSCLC), the five years overall (OS) survival is very poor. Most of the patients developed distant metastasis later which can be improved by induction chemotherapy. Aims: This study was designed to observe the difference in epidemiology, acute toxicities, overall responses [complete response $(C R)+$ partial response $(P R)$ ] after treatment completion, disease-free survival (DFS) and progression-free survival (PFS) at the end of the study. Settings and Design: This was a prospective, interventional, randomized hospital-based study. Methods and Material: Eligible patients were randomized into arm A (CCRT with weekly paclitaxel(P) + Carboplatin(C) with 66 Gray radiation) and arm $B$ (two cycles of induction chemotherapy consisted of $P+C$ followed by CCRT as of arm A. During treatment weekly, after completion of treatment at 6 th week and thereafter 3 monthly evaluation was done till the end of study. Statistical analysis used: Chi-Square and Fisher Exact test did statistical analysis, t-test with 95\%CI, Kaplan Meier survival analysis, Log Rank test using SPSS version 18. Results: Among 44 patients, male (88.6\%), Smokers (85.1\%) were predominant with the most common histology was squamous cell carcinoma (52.4\%). Overall response (Complete Response +Partial Response) was higher in Arm B 66.66\% but statistically nonsignificant. Acute toxicities in both the arms were comparable and similar. DFS and PFS in the induction chemotherapy arm (Arm B) were numerically superior to concurrent chemoradiation arm (Arm A) but statistically nonsignificant Conclusion: To conclude there were no significant differences in results between two arms in the present study population. Further studies with the larger sample size and longer duration of follow up are necessary.

Keywords: Induction chemotherapy, Concurrent chemo-radiation, Lung cancer

Corresponding Author

Lekshmi R Shenoi, Post Graduate Trainee, Department of Radiotherapy, IPGMER and SSKM Hospital, Kolkata, West Bengal, India. Email: pritam.ks1990@gmail.com
How to Cite this Article

To Browse

Sardar PK, Shenoi LR. A prospective study comparing induction chemotherapy followed by chemoradiation versus chemoradiation alone in stage III non-small cell lung cancer. Int J Med Res Rev. 2020;8(1):76-85.

Available From

https://ijmrr.medresearch.in/index.php/ijmrr/article/ view/1131

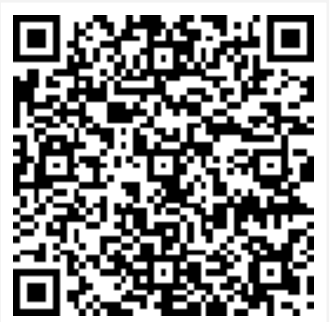

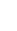




\section{Introduction}

Lung cancer is one of the leading causes of cancer mortality with a rate of increase of $0.5 \%$ per year throughout the world [1]. Approximately $80 \%$ to $90 \%$ of all cases of lung cancer are attributable to voluntary or involuntary cigarette smoke exposure [2]. The risk of lung cancer increases with the number of cigarettes smoked, duration of smoking, earlier age, the tar, and nicotine content [3].

Indoor radon exposure is now considered the second leading cause of lung cancer. Other factors that increase lung cancer risk include exposure to occupational and environmental carcinogens. These are asbestos, arsenic and polycyclic aromatic hydrocarbons [4].

Several genetic alterations are known to occur with lung cancer. These are p53 mutation and deletion on chromosome 3p, 5q, 9p, 11p, and 17p. Genetic modification is more frequent in a smoker than in non- smoker [5].

EGFR activating mutation is seen in approximately $10 \%$ to $15 \%$ of lung cancer patients. These patients are highly sensitive to EGFR TKIs [6]. The role of dietary nutrients did not have any significant causal relation [7].

$85 \%$ of all lung cancer is non-small-cell lung cancer (NSCLC), of which Squamous cell carcinoma is the major histologic variant followed by adenocarcinoma and large cell lung cancer. The relative incidence of adenocarcinoma has increased due to the change in tobacco blends and the use of filters in cigarettes [8].

2015 WHO classification of tumours of the lung, pleura, thymus, and heart has just been published with numerous changes from the 2004 WHO classification.

The most significant changes in this edition are to use of immunohistochemistry throughout the classification to emphasis on genetic studies, in particular, integration of molecular testing to help personalize treatment strategies for advanced lung cancer patients by small biopsies and cytology [12].

Table-1: 2015 who classification of lung cancer

\begin{tabular}{|l|l|}
\hline \multicolumn{1}{|c|}{ Histologic Type and Subtypes } & \multicolumn{1}{c|}{ ICDO Code } \\
\hline Adenocarcinoma & $8140 / 3$ \\
\hline Squamous Cell Carcinoma & $8070 / 3$ \\
\hline Adenosquamous Carcinoma & $8560 / 3$ \\
\hline
\end{tabular}

\begin{tabular}{|l|l|}
\hline Large Cell Carcinoma & $8012 / 3$ \\
\hline Note: ICDO International Classification of Disease for Oncology \\
\hline
\end{tabular}

During disease progression, the vascular or lymphatic invasion occurs which leads to metastatic dissemination to distant sites. Lung cancers can spread to many parts of the body. Bone, liver, adrenal and brain are the most frequent sites of metastatic dissemination.

Metastases within the lung result from a variety of mechanism including endobronchial embolization, retrograde lymphatic, as well as hematogenous dissemination.

The regional lymph node metastases precede the systemic. Ultimately, all of these lymphatic channels drain into the right lymphatic or left thoracic duct, which empties into subclavian veins. Although skip metastases can occur in up to $25 \%$ cases.

The sign and symptoms manifested by lung cancer patients depending on the histology of the tumour and of locoregional invasion, as well as the location, size, and the number of distant metastases.

Up to about $5 \%$ of the patients are asymptomatic and discovered incidentally on chest radiography or CT. Scan. $15 \%$ of cases of lung cancer are localized to the primary site at initial diagnosis, $22 \%$ had regional lymphatic spread, and $56 \%$ distant metastasis; and the remains $7 \%$ are stage unknown.

As most of the lung cancers present in late-stage, they are potentially inoperable, and a chance of distant metastasis is very high [9].

Patients with locally advanced NSCLC, the preferred treatment is platinum-based chemotherapy administered concurrently with RT [10]. Induction chemotherapy may improve systemic control and concurrent chemotherapy appears to increase locoregional control.

Several studies explored the administration of more intensive doublet chemotherapy as induction chemotherapy and during radiotherapy increase overall median survival time than previously achieved with induction (neoadjuvant) chemotherapy alone [11].

Primary Objectives of the study to assess the difference in responses in the two arms, according to RECIST V1.1, in terms of Complete Response $(C R)$, Partial Response (PR), Progressive Disease (PD) and Stable Disease (SD) and the Secondary Objectives are to study the difference between 
Acute toxicities in the arms, with the help of RTOG radiation morbidity criteria (CTC V1.1) and to assess overall survival of one year in both arm, DFS(for complete responders) and PFS(for partial responders and stable disease.

\section{Subjects and Methods}

Before the inception of the study, an application was submitted to the institutional ethics committee (IEC). After proper scrutiny and detailed review, IEC approved the research proposal. Informed consent was taken in three languages (English, Bengali, Hindi). The trial was registered on the Clinical Trial Registry of India to obtain a CTRI no.

Patient selection and randomization: This was a prospective, interventional, randomized study in a tertiary care hospital. After confirmation of diagnosis by CT guided core needle biopsy, newly diagnosed 44 non-metastatic non-small cell lung cancer patients attending the radiotherapy OPD, aged 18 to 70 years, having good performance status(ECOG 0-2), without any severe systemic comorbidities or uncontrolled severe hematological abnormalities and have inoperable stage IIIA and IIIB disease [T1N2, T2N2, T3N1, T3N2, T4N0, T4N1 (Stage IIIA) and T1N3, T2N3, T3N3, T4N2, T4N3 (Stage IIIB)] were included in this study in the period of January 2016 to August 2017. Pregnant patients were excluded. Eligible 44 patients for study were randomized into two arms by lottery.

Study design: 23 patients of ARM-A received CCRT with weekly paclitaxel $50 \mathrm{mg} / \mathrm{m} 2$ and carboplatin (area under a curve, AUC-2) intravenously. 21 patients of ARM-B received two cycles of induction chemotherapy consisted of paclitaxel $200 \mathrm{mg} / \mathrm{m} 2$ and carboplatin (AUC-6)intravenously every 21 days prior to CCRT.

For both arms patients received 66Gy radiation dose at $2 \mathrm{~Gy} /$ fraction at five fractions per week from Monday to Friday per week for 6 weeks 3days once in a day. Usually, every patient received chemotherapy on Monday after a routine check-up.

Paclitaxel is an $M$ phase-specific chemotherapeutic drugs acts by microtubule polymerization. carboplatin is a non-cell cycle specific drug acts by DNA adduct formation. For both arms' paclitaxel was infused first in $500 \mathrm{ml}$ normal saline bottle for $1 \mathrm{hr}$ (for concurrent chemo) and 3 hours (for induction chemo).
In 2 nd bottle. All patients received tab. Avil 50mg, Injection Dexamethasone $20 \mathrm{mg}$, Injection Ondansetron $16 \mathrm{mg}$ and Injection Ranitidine $50 \mathrm{mg}$ as premedication.

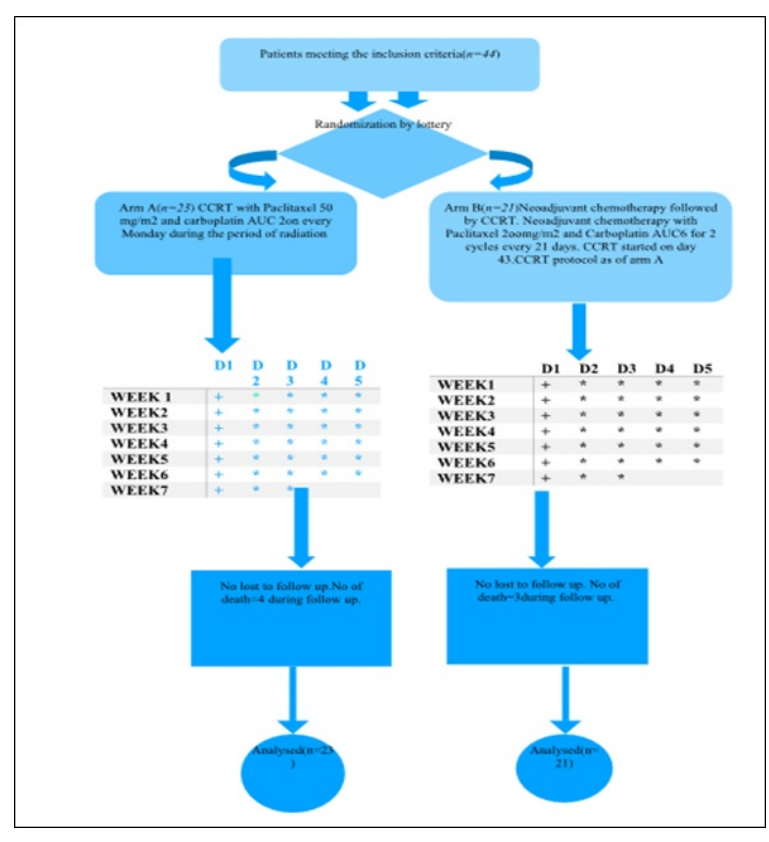

+: CCRT days
*: Only RT days

Fig-1: Consort diagram

EBRT Planning: Radiation treatment was executed in Bhabatron II (Cobalt-60) treatment unit with a planning software ONCENTRA (version-4.5.2.23). While taking CT images in CT simulator (PANACEA), patients were lying in the supine position with both arms above the head and the same was sent to ONCENTRA (version- 4.5.2.23) software for contouring of External, GTV, CTV and PTV and planning.

The clinically macroscopic diseases typically identified on imaging were contoured as gross tumour volume (GTV, GTV node). The clinical target volume (CTV) represents a volumetric expansion of the GTV to encompass microscopic disease. For squamous cell carcinoma $6 \mathrm{~mm}$ expansions and for adenocarcinoma $8 \mathrm{~mm}$ margins were given. For lymph nodes, 3-5 $\mathrm{mm}$ expansions were given as per the size of the disease. The planning target volume (PTV) is a volumetric expansion of the CTV to account for set-up variability.

The PTV was generated by giving a margin of $2 \mathrm{~cm}$ three-dimensionally. Dose constraints for bilateral lungs excluding the PTV, esophagus, heart, spinal 
Cord were considered. According to QUANTEC (Quantitative Analysis of Normal Tissue Effects In The Clinic) data for lung, the dose constraint is V20<30-35 Gy (V20 is defined as the percentage of normal lung receiving at least 20 gray and is dependent on the total lung volume)with conventional fractionation in the dose-volume histogram (DVH).

For esophagus, the collected data suggest that volumes treated at more than 40-50 Gy correlate to acute symptoms and that no dose above prescription is allowed to even small volumes of the esophagus. For heart and pericardium, the dose conclusion of QUANTEC data reflects the conservative interpretation of existing literature.

If the V25 is less than $10 \%$, then the excess risk of cardiac mortality attributable to ischemic changes is less than $1 \%$ at 15 yrs. The risk of pericarditis can be minimized by keeping pericardial V $30<46 \%$. For the spinal cord, the dose constraint is $45 \mathrm{~Gy}$ using $1.8 \mathrm{~Gy}$ fractions.

Dose prescription: Generally for Phase I, AP-PA fields were used to treat the patients.If required multiple fields were used such as 3 fields (AP and two lateral fields). For Phase I the prescribed dose is $46 \mathrm{~Gy}$ in 23 fractions, 5 fractions/ week in 4.5 weeks dose to be prescribed at midplane for AP-PA field.

For Phase 2 generally, 3 fields were used for better optimal dose distribution. The dose was $20 \mathrm{~Gy}$ in 10 fractions, 5 fractions/ week in 2 weeks. Dose to be prescribed at normalization point on GTV.

Evaluation and Follow up: Patients were evaluated for acute toxicity in each week on Monday during radiation therapy by physical examination and blood for CBC and Urea, Creatinine. They were graded according to the RTOG Radiation Morbidity Criteria.

For assessment of clinical response in terms of complete response (CR), partial response (PR), progressive disease (PD), and stable disease (SD), RECIST (Response Evaluation Criteria in Solid Tumor) was used.

Patients were assessed at 6 weeks after completion of treatment by CECT thorax, USG whole abdomen, blood for CBC, LFT, Ur, Cr. Thereafter every 12weekly interval till the end of the study by physical examination, chest X-ray digital PA view, blood for CBC, LFT, Ur, Cr. If there was any suspected lesion, a CECT scan of that region was advised.
Recurrence was proved with either biopsy or FNAC. In the case of suspected brain metastasis, MRI gadolinium contrast of brain was advised.

Statistical analysis: Statistical analysis was done using SPSS version 18. Chi Square and Fisher Exact test were used, while for continuous variables, the mean and SD were compared using an independent samples t-test with $95 \% \mathrm{CI}$.

All tests were two-tailed and a $p$-value less than 0.05 was taken as significant. The disease-free survival was determined using the Kaplan Meier survival analysis with the Log Rank test for comparing the DFS.

\section{Results}

Table-2: Demographic Analysis

\begin{tabular}{|c|c|c|c|c|}
\hline Category & Total & $\operatorname{Arm} \mathbf{A}$ & Arm B & P-Value \\
\hline & n (\%) & n (\%) & n (\%) & \\
\hline & 44 & $23(52.3)$ & $21(47.7)$ & \\
\hline Age (Mean and $95 \% \mathrm{CI}$ & & $55.91 \pm 3.33$ & $55.05 \pm 2.77$ & 0.70 \\
\hline \multicolumn{5}{|l|}{ Gender } \\
\hline Male & $39(88.6)$ & $19(82.6)$ & $20(95.2)$ & \\
\hline Female & $5(11.4)$ & $4(17.4)$ & $1(4.1)$ & 0.19 \\
\hline \multicolumn{5}{|l|}{ Addiction } \\
\hline Smoker & $37(84.1)$ & $19(82.6)$ & $18(85.7)$ & \\
\hline Non-Smoker & $7(15.9)$ & $4(17.4)$ & $3(14.3)$ & 0.78 \\
\hline \multicolumn{5}{|l|}{ Histology } \\
\hline Adenocarcinoma & $13(29.5)$ & $7(30.4)$ & $6(28.6)$ & \\
\hline Squamous cell carcinoma & $23(52.3)$ & $12(52.2)$ & $11(52.4)$ & \\
\hline Large cell carcinoma & $3(6.8)$ & $2(8.7)$ & $1(4.8)$ & 0.67 \\
\hline Broncho Alveolar Carcinoma & $4(9.1)$ & $1(4.3)$ & $3(14.3)$ & \\
\hline Other & & $1(4.3)$ & $0(0)$ & \\
\hline \multicolumn{5}{|l|}{ ECOG performance status } \\
\hline PSO & $5(11.4)$ & $3(13.3)$ & $2(9.5)$ & \\
\hline PS1 & $20(45.5)$ & $11(47.8)$ & $9(42.9)$ & 0.83 \\
\hline PS2 & 19(43.2) & $9(39.1)$ & $10(47.6)$ & \\
\hline \multicolumn{5}{|l|}{ Tumor Stage } \\
\hline T1 & $0(0)$ & $0(0)$ & $0(0)$ & \\
\hline $\mathrm{T} 2$ & $8(18.2)$ & $4(17.4)$ & $4(19.0)$ & 0.78 \\
\hline T3 & $19(43.2)$ & $9(39.1)$ & $10(47.6)$ & \\
\hline T4 & $17(38.6)$ & $10(43.5)$ & $7(33.3)$ & \\
\hline \multicolumn{5}{|l|}{ Nodal Stage } \\
\hline No & $3(6.8)$ & $1(4.3)$ & $2(9.5)$ & \\
\hline N1 & $11(25.0)$ & $5(21.7)$ & $6(28.6)$ & 0.83 \\
\hline N2 & $19(43.2)$ & $11(47.8)$ & $8(38.1)$ & \\
\hline N3 & $11(25.0)$ & $6(26.1)$ & $5(23.8)$ & \\
\hline
\end{tabular}

Demographic analysis: 44 patients were randomized into two arms.88.6\% were male, with a mean age of diagnosis were $(55.91 \pm 3.33)$ years in 
Arm A and $(55.05 \pm 2.77)$ years in Arm B. Smokers were $84.1 \%$.The most common histology was squamous cell carcinoma(52.3\%)followed by adenocarcinoma (29.5\%).

Response assessment: Overall response rate 4-6 week after completion of treatment was assessed by RECIST criteria. In Arm A, the overall response rate (Complete Response + Partial Response) was 60.9\% and in Arm B it was $66.7 \%(p=0.9)$.

With a mean follow up of 10.8 months in Arm $A$ and 7.5 months in Arm B, Arm B showed numerically superior values than Arm A in terms of DFS ( $p$ value- 0.542$)$ and PFS(Log Rank test value $=0.042)$.

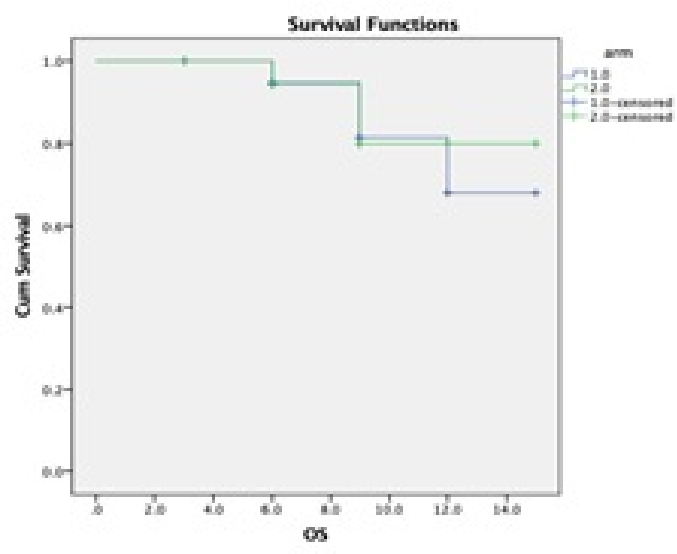

Fig-2: Kaplan Meier survival analysis of overall survival.

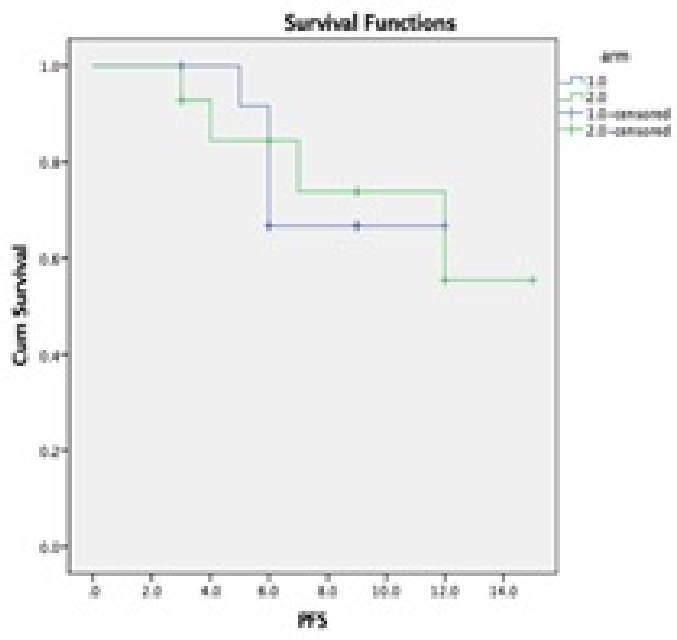

Fig-3: Kaplan-Meier survival analysis of progression free survival.

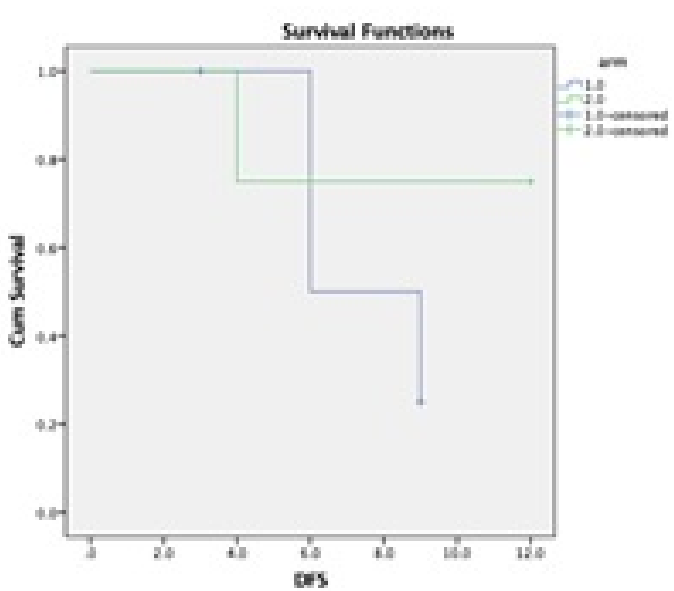

Fig-4: Kaplan-Meier analysis of disease-free survival.

Toxicity assessment: The treatment was very tolerated in the current study. Acute hematological toxicity ( $p$ value $=0.212)$ acute lung toxicity $(p$ value $=0.329)$, acute pharynx and esophagus toxicity ( $p$ value $=0.049)$ and skin toxicity $(p$ value $=0.725$ ) were similar in induction chemotherapy arm (Arm B) with respect to arm A.

\begin{tabular}{|c|c|c|c|}
\hline & $\operatorname{Arm} \mathbf{A}$ & Arm B & P-Value \\
\hline \multicolumn{4}{|c|}{ RTOG lung toxicity } \\
\hline Grade 0 & 11 & 6 & \multirow[t]{4}{*}{0.335} \\
\hline Grade 1 & 8 & 11 & \\
\hline Grade 2 & 3 & 4 & \\
\hline Grade 3 & 1 & 0 & \\
\hline \multicolumn{4}{|c|}{ RTOG upper GI toxicity } \\
\hline Grade 0 & 11 & 4 & \multirow[t]{4}{*}{0.048} \\
\hline Grade 1 & 9 & 12 & \\
\hline Grade 2 & 3 & 3 & \\
\hline Grade 3 & 0 & 2 & \\
\hline \multicolumn{4}{|c|}{ RTOG Skin Toxicity } \\
\hline Grade 0 & 18 & 17 & \multirow[t]{4}{*}{0.73} \\
\hline Grade 1 & 3 & 4 & \\
\hline Grade 2 & 2 & 0 & \\
\hline Grade 3 & 0 & 0 & \\
\hline \multicolumn{4}{|c|}{ RTOG Hematological Toxicity } \\
\hline Grade 0 & 9 & 12 & \multirow[t]{4}{*}{0.216} \\
\hline Grade 2 & 10 & 7 & \\
\hline Grade 3 & 3 & 2 & \\
\hline Grade 4 & 1 & 0 & \\
\hline
\end{tabular}

\section{Discussion}

Lung cancer is one of the most common malignancies worldwide. In my study, $88.6 \%$ of patients were male with a mean age of diagnosis 


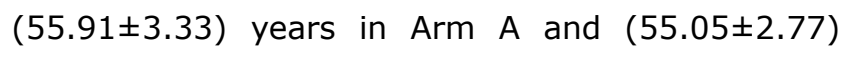
years in Arm B. Among them $84.1 \%$ of patients were smokers. This data is corroborative with the world incidence of lung cancer in smokers [13].

Analysis of data from 22 cancer registries in 5 continents revealed that cumulative lung cancer risks were higher in males than in females [14]. Approximately $80 \%$ of non-small lung cancer (NSCLC) in men worldwide are directly attributable to cigarette smoking [15]. These features were also encountered in the present study population.

The patients were diagnosed by $\mathrm{CT}$ guided trust biopsy or bronchoscopic biopsy. Adenocarcinoma $(29.5 \%)$ followed by squamous cell carcinoma (52.3\%) was the most common type of histology. The rising trend of adenocarcinoma in the last 30 years is seen [16]. The therapeutic approach in unresectable non-small-cell lung cancer is widely discussed and a debatable one.

The optimum treatment modality is yet to be defined. Induction chemotherapy has several theoretical advantages, including reducing tumor volume, enhancing local control, treating micrometastatic disease, and being better tolerated. The current study had two arms Arm A-concurrent chemo-radiotherapy and Arm B-two cycles induction chemotherapy followed by concurrent chemoradiotherapy.

Baseline profiles of both groups were comparable in terms of age and sex distribution, performance status, tumor status, and nodal status. This study was an attempt to report our experience with induction chemotherapy followed by concurrent chemo-radiotherapy in locally advanced unresectable non-small cell lung cancer. There are few trials that have reported on the use of induction chemotherapy followed by chemo-radiotherapy.

Dose-escalating conformal thoracic radiation
therapy with induction and concurrent carboplatin/paclitaxel in unresectable stage IIIA/B non-small cell lung carcinoma: a modified phase I/II trial, a study by Mark A. Socinski et al [16] showed the response rate was $40 \%$ to induction carboplatin/paclitaxel. 8 patients (13\%) progressed on the induction phase.

The major toxicity was esophagitis, however, only $8 \%$ developed Grade 3/4 esophagitis using Radiation Therapy Oncology Group criteria. The overall response rate was $52 \%$. Survival rates at 1 , 2,3 , and 4 years were $71 \%, 52 \%, 40 \%$, and $36 \%$,
Respectively, with a median survival of 26 months. The 1, 2, and 3-year progression-free survival probabilities were $47 \%, 35 \%$, and $29 \%$, respectively.

The study concluded, Incorporation of TCRT with sequential and concurrent carboplatin/paclitaxel is feasible, with acceptable toxicity. Overall response and survival rates are encouraging. Both locoregional and distant failure remain problematic in this population of patients.

Randomized phase II study of cisplatin with gemcitabine or paclitaxel or vinorelbine as induction chemotherapy followed by concomitant chemoradiotherapy for stage IIIB non-small-cell lung cancer: Cancer and Leukemia Group B study done by Everett E. Vokes et al [17] between July 1998 and May 2002, where 366 patients were randomly assigned to arm A, which involved immediate concurrent chemoradiotherapy with carboplatin area under the concentration-time curve (AUC) of 2 and paclitaxel $50 \mathrm{mg} / \mathrm{m} 2$ given weekly during 66 Gy of chest radiotherapy, or arm B, which involved two cycles of carboplatin AUC 6 and paclitaxel $200 \mathrm{mg} / \mathrm{m} 2$ administered every 21 days followed by identical chemoradiotherapy.

This study concluded that the addition of induction chemotherapy to concurrent chemoradiotherapy added toxicity and provided no survival benefit over concurrent chemoradiotherapy alone. The median survival achieved in each of the treatment groups is low, and the routine use of weekly carboplatin and paclitaxel with simultaneous radiotherapy should be re-examined.

A phase II study of induction chemotherapy followed by concurrent chemoradiotherapy in elderly patients with locally advanced non-small-cell lung cancer, done by Giorgio CG et al [18]observed complete and partial responses in 1 and 19 of the 30 patients, respectively, for an overall response rate of $66 \%$ (95\% confidence interval, $45-76 \%$ ).

Median progression-free survival was 8.7 months (95\% confidence interval, 3.4-37.8) and median survival was 15 months ( $95 \%$ confidence interval, 4.2-52.1). During the treatment, 12 patients (40.0\%) experienced grade 3-4 neutropenia, two patients' neutropenic fever, and three patients grade 3 anemia and grade 3 thrombocytopenia, respectively. Grade 3 oesophagitis, during concomitant radiotherapy, was observed in six patients $(20.0 \%)$. 
No treatment-related mortality was reported. They concluded induction chemotherapy followed by concurrent chemoradiotherapy appears safe and seems a reasonable chance for the treatment of locally advanced non-small-cell lung cancer in the elderly population.

A Phase II Study of Induction Chemotherapy Followed by Thoracic Radiotherapy and Erlotinib in Poor-Risk Stage III Non-Small-Cell Lung Cancer: Results of CALGB 30605 (Alliance)/RTOG 0972 (NRG) by ] Lilenbaum $R$ et al [19] concluded that patients with poor-risk stage III non-small-cell lung cancer had better than expected outcomes with a regimen of induction carboplatin/nab-paclitaxel followed by thoracic radiotherapy and erlotinib. However, as per the statistical design, the 12-month OS was not sufficiently high to warrant further studies.

Induction Chemotherapy Followed by Concurrent Chemoradiotherapy in Stage III Unresectable Nonsmall Cell Lung Cancer, a study done by Eng Eng $\mathrm{H}$. Tan et al [20] said the favorable experience with the combination regimen of vinorelbine, ifosfamide, and cisplatin (NIP) The NIP regimen results in a high response rate in NSCLC and this treatment program seems to benefit selected patients with stage III disease.

Induction chemotherapy followed by concurrent chemotherapy and definitive high dose radiotherapy for patients with locally advanced non-small-cell lung cancer (stages III a/ III b): a pilot phase I/II trial done by $C$. Pottgen et al [21] showed the main endpoint of this study-turned out to be acceptable (oesophagitis grade 3/4: 6/4 patients; pneumonitis grade 3/4: $0 / 1$ patients; no treatment-related deaths). Actuarial survival at 2 years was $31 \%$ with a loco-regional control rate of $21 \%$. This regimen turned out to be feasible with acceptable toxicity.

Induction chemotherapy followed by concurrent chemoradiotherapy (CCRT) versus CCRT alone for unresectable stage III non-small cell lung cancer (NSCLC): randomized phase III trial, a study by Min Kyoung Kim et al [22] concluded that the addition of induction chemotherapy to CCRT failed to increase the survival of unresectable stage III NSCLC over immediate CCRT. Moreover, progression-free survival was inferior to immediate CCRT.

The LAMP [23] (Locally Advanced Multimodality Protocol) [24] Phase II randomized study compared 276 patients stage IIIA and B patients median survival, after a follow up of 39.6 months, was
Higher in the arm receiving concurrent chemoradiotherapy followed by chemotherapy, with a median survival of 16.3 month vs 13 month in the sequential arm, and 12.7 month for induction chemotherapy followed by concurrent chemoradiotherapy. Chemotherapy was with carboplatin and paclitaxel.

Iranzo $V$ et al [24] included 31 patients with NSCLC Stage IIIA and $B$, median age 66 years, $16.2 \%$ of the patients achieved a complete response,48.4\% partial response, $25.8 \%$ stable disease and $9.6 \%$ progression of the disease, median progressionfree, and overall survival was 12 and 18 months respectively.

Patients received 3 courses of induction $\mathrm{CT}$ with carboplatin $(A \cup C=6)$ and paclitaxel $175 \mathrm{mg} / \mathrm{m} 2$ administered IV on day-1 of each 21 days cycles followed by thoracic irradiation (Total dose 60-65 GY daily fraction 1.8-2 GY) with two concurrent courses of carboplatin/paclitaxel.

The most frequent hematological toxicities were Grade 3 anemia in $19.3 \%$, Grade 3 neutropenia in $9.6 \%$ and Grade 4 neutropenia in $12.9 \%$. Esophageal Grade 2 toxicity was observed in $28.1 \%$ of cases. The induction CT followed by concomitant chemoradiation used in this study appears feasible, safe and effective.

Hirsh et al [25] Phase -II trial with carboplatin/gemcitabine induction chemotherapy followed by radiotherapy concomitantly with paclitaxel/gemcitabine(P/G) in stage III NSCLC.27 males, 14 females, median age 60 years (37-70 years) of first 38 evaluable patients after induction chemotherapy, partial response (PR) was 74\%(28 patients), stable disease (SD) 24\%(9patients) and $2 \%$ (1patient) had progressive disease(PD). The toxicity of induction CT was minimal.

In the present study overall response rate was $66.66 \%$ in induction chemotherapy arm and Iranzo $V$ et al [24] reported a $64.6 \%$ overall response rate in a similar study. With a mean follow up of 10.8 months in Arm A and 7.5 months in Arm B, Arm B showed numerically superior values than Arm $A$ in terms of DFS ( $p$-value- 0.542)and PFS(Log Rank test value $=0.042$ ).

But both values are non-significant. The treatment was very tolerated in the present study. Acute haematological toxicity ( $p$ - value $=0.212$ ), acute lung toxicity ( $p$ value $=0.329$, , acute pharynx and oesophagus toxicity ( $p$ value $=0.049$ ) and skin 
Toxicity $(p$ value $=0.725)$ were similar in induction chemotherapy arm (Arm B) with respect to arm A.

The limitations of the study are

01. Short follow up duration as this cancer recurs within 24 months, more so in the first twelve months post-treatment. The entire study duration was almost 1.5 years including patient accrual, intervention, and assessment. So, the toxicity profile or DFS/PFS may be changed with longer follow up.

02. In the analysis, contributing factors such as anemia, duration of treatment interruption, OTT, deterioration of nutritional status with fall in QOL were not adjusted for assessing the response rate and DFS/PFS.

03. As the duration of the study was small, the analysis of chronic toxicity was not included in the study. The sample size was small, so any statistical data have to be interpreted with caution.

04. Being a single institutional study; results derived cannot be extrapolated on the entire population.

\section{Conclusions}

The treatment was very tolerated in the present study with a high overall response rate. Acute hematological toxicity ( $p$ value $=0.212$ ), acute lung toxicity $(\mathrm{p}$ value $=0.329)$, acute pharynx and esophagus toxicity ( $p$ value $=0.049$ ) and skin toxicity $(p$ value $=0.725)$ were similar in induction chemotherapy arm (Arm B) with respect to arm A.

\section{What does the study add to the existing knowledge}

The treatment of choice for stage III inoperable NSCLC is concurrent chemoradiation. In spite of the treatment, the median life expectancy for stage III NSCLC is around 15 months for stage IIIA and 13 months for stage IIIB. The 5 -year survival rate is sadly $23 \%$ for stage IIIA and around $10 \%$ for stage IIIB. The main drawback of the treatment modality is RTOG grade $3 / 4$ toxicities especially upper GI toxicities. In the current study, the early results are very promising. The mean overall survival time was greater than that of the standard arm (13.329 vs 13.628 months).

Disease-free survival (7.5 months vs 10 months) and progression-free survival (9.917 months vs
11.816 months) was also greater than that of the conventional arm. Although none of the data achieved statistical significance. In the present study, most of the patients from the comparator arm suffered from RTOG grade 2 upper GI toxicity. Two patients suffered from grade 3 upper GI toxicity for which treatment interruption was required. The rest of the toxicity patterns were comparable in both the arms. In short, the study arm is feasible and it showed more efficacy than the standard arm in early results.

\section{Author's contribution}

Dr. Pritam K Sardar: Concepts, design, literature search, data analysis, manuscript preparation

Dr. Lekshmi R Shenoi: Design, literature search, data acquisition, data analysis, manuscript preparation

\section{Reference}

01. Magrath I, Litvak J. Cancer in developing countries- opportunity and challenge. JNCI- J Nat Cancer Inst. 1993;85(11)862-874.

doi: [Article] [Crossref]

02. Jemal A, Bray F, Center MM, Ferlay J, Ward E, Forman D. Global cancer statistics. CA- Cancer J Clin. 2011;61(2)69-90.

doi: [Article] [Crossref]

03. Loeb LA, Emster VL, Warner KE, Abbotts J, Laszlo J. Smoking and Lung Cancer- An Overview. Am Assoc Cancer Res. 1984;44(12)5940-5958.

[Crossref]

04. Zahm SH, Brownson RC, Chang JC, Davis JR. Study of lung cancer histologic types, occupation, and smoking in Missouri. Am J Indus Med. 1989;15(5)565-578.

doi: [Article] [Crossref]

05. Don L. Gibbons, Lauren A Byers, and Jonathan M Kurie. Smoking, p53 Mutation, and Lung Cancer. Mol Cancer Res.

2014;12(1)3-13. doi: [Article] [Crossref]

06. Lynch TJ, Bell DW, Sordella R, Gurubhagavatula S, Okimoto RA, Brannigan BW, et al. Activating mutations in the epidermal growth factor receptor underlying responsiveness of nonsmall-cell lung cancer to gefitinib. New Eng J Med. 2004;350(21)2129-2139.

doi: [Article] [Crossref] 
07. Alberg AJ, Samet JM. Epidemiology of lung cancer. Chest. 2003;123(1)21S-49S.

doi: [Article] [Crossref]

08. Valaitis J, Warren S, Gamble D. Increasing incidence of adenocarcinoma of the lung. Cancer. 1981;47(5)1042-1046.

doi: [Article] [Crossref]

09. Perez and Brady. Principles and Practice of Radiation Oncology. 5th edition. 2008;48;1083. [Crossref]

10. Schaake-Koning C, Van den Bogaert, W Dalesio, Festen J, Hoogenhout J, van Houtte $P$, Kirkpatrick A, Koolen M, Maat B, Nijs A. Effects of concomitant cisplatin and radiotherapy on inoperable non-small cell lung cancer. New Eng) J Med. 1992;326(8)524-530. doi: [Article] [Crossref]

11. Takeda K, Negoro S, Tanaka M, Fukuda $H$, Nakagawa K, Kawahara $M$, et al. A phase II study of cisplatin and irinotecan as induction chemotherapy followed by concomitant thoracic radiotherapy with weekly low-dose irinotecan in unresectable, stage III, non-small cell lung cancer- JCOG 9706. Japan J Clin Oncol. 2011;41(1)25-31.

doi: [Article] [Crossref]

12. Travis WD, Brambilla $E$, Nicholson AG, Yatabe $Y$, Austin JH, Beasley MB, et al. The 2015 World Health Organization classification of lung tumors: impact of genetic, clinical and radiologic advances since the 2004 classification. J Thorac Oncol. 2015;10(9)1243-1260.

doi: [Article] [Crossref]

13. Thun MJ, DeLancey JO, Center MM, Jemal A, Ward EM. The global burden of cancer- priorities for prevention. Carcinogenesis. 2010;31(1)100110.

doi: [Article] [Crossref]

14. Sano $H$, Marugame $T$. International Comparisons of Cumulative Risk of Lung Cancer, From Cancer Incidence in Five Continents Vol VIII. Japan J Clin Oncol. 2006;36(5)334-335. doi: [Article] [Crossref]

15. Levin ML, Goldstein H, Gerhardt PR. Cancer and tobacco smoking- a preliminary report. J Am Med Assoc. 1950;143(4)336-338.

doi: [Article] [Crossref]
16. Socinski MA, Rosenman JG, Halle J, Schell MJ, Lin $Y$, Russo $S$, et al. Dose-escalating conformal thoracic radiation therapy with induction and concurrent carboplatin/paclitaxel in unresectable stage IIIA/B nonsmall cell lung carcinoma- a modified phase I/II trial. CancerInterdisciplinary Int $\mathrm{J}$ Am Cancer Soc. 2001;92(5)1213-1223. doi: [Article] [Crossref]

17. Vokes EE, Herndon JE, Crawford J, Leopold KA, Perry MC, Miller AA, et al. Randomized phase II study of cisplatin with gemcitabine or paclitaxel or vinorelbine as induction chemotherapy followed by concomitant chemoradiotherapy for stage IIIB non-small-cell lung cancer- Cancer and Leukemia Group B study 9431. J Clin Oncol. 2002;20(20)4191-4198.

doi: [Article] [Crossref]

18. Giorgio CG, Pappalardo A, Russo A, Santini D, Di Rosa C, Di Salvo C, et al. A phase II study of induction chemotherapy followed by concurrent chemoradiotherapy in elderly patients with locally advanced non-small-cell lung cancer. Anticancer drugs. 2007;18(6)713-719.

doi: [Article] [Crossref]

19. Lilenbaum $R$, Samuels $M$, Wang $X$, Kong $F M$, Jänne PA, Masters G, et al. A Phase II Study of Induction Chemotherapy Followed by Thoracic Radiotherapy and Erlotinib in Poor-Risk Stage III Non-Small-Cell Lung Cancer- Results of CALGB 30605 (Alliance)/RTOG 0972 (NRG). J Thorac Oncol. 2015;10(1)143-147.

doi: [Article] [Crossref]

20. Eng $\mathrm{H}$ Tan, Joseph Wee, Peng $\mathrm{T}$ Ang, Kam W Fong, Swan S Leong, Kei S Khoo, et al. Induction Chemotherapy Followed by Concurrent Chemoradiotherapy in Stage III Unresectable Non-small Cell Lung Cancer. Acta Oncologica. 2009;38(8)1005-1009.

doi: [Article] [Crossref]

21. Pöttgen C, Eberhardt W, Bildat S, Stüben G, Stamatis G, Hillejan $L$, et al. Induction chemotherapy followed by concurrent chemotherapy and definitive high-dose radiotherapy for patients with locally advanced non-small-cell lung cancer (stages IIIa/IIIb)- a pilot phase I/II trial. Ann Oncol. 2002;13(3)403-411.

doi: [Article] [Crossref] 
22. Kima MK, Kima SW, Choi EK, Sohn HJ, Lee DH, Suh $\mathrm{C}$, et al. A1-01- Induction chemotherapy followed by concurrent chemoradiotherapy (CCRT) versus CCRT alone for unresectable stage III non-small cell lung cancer (NSCLC)randomized phase III trial. J Thorac Oncol. 2007;2(8)S308.

doi: [Article] [Crossref]

23. Belani $C P$, Choy $H$, Bonomi $P$, Scott $C$, Travis $P$, Haluschak $J$, et al. Combined chemoradiotherapy regimens of paclitaxel and carboplatin for locally advanced non-small-cell lung cancer- a randomized phase II locally advanced multi-modality protocol. J Clin Oncol. 2005;23(25)5883-5891.

Epub 2005 Aug 8. doi: [Article] [Crossref]
24. Iranzo $V$, Bremnes RM, Almendros $P$, Gavila J, Blasco A, Sirera R et al. Induction chemotherapy followed by concurrent chemoradiation for patients with non-operable stage III non-smallcell lung cancer. Lung Cancer. 2009;63(1)63-67. doi: [Article] [Crossref]

25. Hirsh V, Soulieres D, Duclos M, Faria S, Vecchio $P D$, Ofiara $L$ et al. Phase II multicenter trial with carboplatin and gemcitabine induction chemotherapy followed by radiotherapy concomitantly with low-dose paclitaxel and gemcitabine for stage IIIA and IIIB non-small cell lung cancer. J Thorac Oncol. 2007;2(10)927-932.

doi: [Article] [Crossref] 